Revista Peruana de Derecho Internacional

Tomo LXX Enero-A6ril $2020 \mathcal{N}^{\circ} 164$, pp. 261-262.

ISSN: 2663-0222

\title{
Chanamé Orbe, Raúl. Tratado de Derecho Constitucional. Lima: Instituto Pacífico, 2019, pp. 863.
}

Conocí al profesor Chanamé como jurado de mi examen de ingreso al Doctorado en Derecho y Ciencia Política, en la Universidad Nacional Mayor de San Marcos, a comienzos del año 2019. En esa ocasión, Chanamé fue estricto, pero también fraterno, dándome la grata bienvenida a la Decana de América.

La emoción de ese resultado se ve renovada con el privilegio de leer y reseñar la primera edición de su Tratado de Derecho Constitucional, una de las obras que, no solo resume el camino y la sapiencia jurídica de uno de los más notables exponentes del derecho constitucional peruano, sino que estoy seguro se convertirá en una lectura de carácter imprescindible para las nuevas generaciones de constitucionalistas y aquellos que, especializados en otras ramas del Derecho, requieran de una obra de consulta en derecho constitucional.

Me gustaría en este espacio resaltar, muy sucintamente, algunos puntos notables de esta contribución tratadística, y que me han llamado gratamente la atención, desde la óptica del derecho internacional. Adoptar este enfoque supone, además, un mayor rigor en torno a la valoración de esta obra, puesto que supone descubrir el valor del Tratado de Derecho Constitucional desde un ángulo que no es el central, pero no por ello menos importante, en el contexto del libro.

Una de las ideas más resaltantes es que el autor destaca que el derecho constitucional tiene relación con otras ramas jurídicas, entre ellas, el derecho internacional. Así lo sostiene Chanamé, respecto al derecho de gentes, al señalar que las constituciones comprenden temas relativos a la "suscripción a los tratados, las formas asociativas entre los países, la sujeción a los organismos supranacionales, la forma del establecimiento de las relaciones diplomáticas" (pp. $79-80)$.

En ese sendero, dos aspectos llaman la atención transversalmente.

En primer lugar, resulta sumamente atrayente el capítulo XII del libro, relativo a la teoría del Estado y poderes constitucionales, puesto que brinda una aproximación balanceada del origen de este concepto, destacando las características de territorialidad, soberanía, constitucionalidad, burocracia pública y poder legítimo del Estado moderno, el cual es un sujeto central en el estudio del derecho internacional clásico, y que pervive en el contemporáneo. Asimismo, Chanamé ofrece un desarrollo estricto de los elementos del Estado, también explorados por múltiples autores del derecho internacional, y una síntesis muy interesante de los principales teóricos del Estado. En un siguiente capítulo, examina, además, otro aspecto estatal que desarrollan también internacionalistas de la talla de Charles Rousseau, relativo a las formas de Estados unitarios y compuestos. Todo ello conduce a apreciar la seriedad y profundidad del maestro sanmarquino en el tratamiento de su materia. 
En segundo lugar, el autor explora la definición que la doctrina da a los derechos humanos (pp. 272-273), las generaciones de derechos (pp. 338-339), los principios que los sustentan (pp. 273-275) y su interrelación con los derechos fundamentales (pp. 209- 211); aspectos esenciales en el estudio del actual derecho internacional de los derechos humanos. Además de examinar derechos en concreto en los capítulos VIII, IX y X. En este punto, una humilde recomendación del discente a este eximio aporte, si es posible alguna, es contar también, en una próxima edición, un capítulo (o apartado) sobre el Perú y los sistemas de protección de derechos humanos, entre ellos, el universal y el interamericano.

En síntesis, me gustaría concluir felicitando al profesor Chanamé por su magnum opus, que es uno de los textos más serios y mejor logrados de derecho constitucional, de manos de un autor peruano y respetado profesor sanmarquino, por lo que, indudablemente, constituye una contribución imprescindible para los estudios de derecho constitucional en nuestro país y a nivel de la región. El autor contribuye con su Tratado, de manera indudable, a la forja de una nueva generación de juristas preocupados en lograr, cada vez más, la promoción y protección de la dignidad del ser humano.

Prof. Pablo César Rosales Zamora*

\footnotetext{
* Doctorando en Derecho y Ciencia Política por la Universidad Nacional Mayor de San Marcos (UNMSM). Profesor de Derecho Internacional en la Facultad de Derecho de la Universidad de San Martín de Porres (USMP) y de Derecho Internacional Privado en la Facultad de Derecho y Ciencia Política de la Universidad Católica Sedes Sapientiae (UCSS). Asesor en la Oficina de Derecho Internacional Público del Ministerio de Relaciones Exteriores del Perú.
} 